\title{
Research on the Influence of Chinese Aesthetics on Fashion Design
}

\author{
SiYu Guo ${ }^{1}$, Jian Xiao ${ }^{1 *}$ \\ ${ }^{1}$ Dalian Polytechnic University \\ *Corresponding author. Email: 497524298@qq.com
}

\begin{abstract}
With the rapid development of economic, cultural and science and technology, China's fashion industry is also developing vigorously with the times. "Chinese Aesthetics" gets the favor and application of global fashion. Through the collection of fashion information at home and abroad, this paper summarizes the definition and characteristics of fashion, analyzes the current situation of global fashion development, expounds the Chinese elements in contemporary Chinese style clothing design and Western apparel design, and understands the contemporary "Chinese Aesthetics" and the design styles of some aggressive designer, and how to give new content to Chinese aesthetics in the post-epidemic era.
\end{abstract}

Keywords: Chinese aesthetics, Fashion Design, Research

\section{INTRODUCTION}

Chinese aesthetic design has been common in the global fashion circle, which is the confirmation of China's continuous development and improvement of world status, but also the proof that Chinese elements and exquisite Chinese craftsmanship have attracted the attention of the world. However, whether in the past or now, the West has always lacked an objective understanding of Chinese aesthetics. Chinese aesthetics is not a simple accumulation of Chinese traditional elements, andit has its unique artistic conception and charm. Study the influence of Chinese aesthetics on fashion design, and convey the unique artistic conception of Chinese culture. ${ }^{[1]}$

\section{OVERVIEW OF CHINESE AESTHETICS}

\subsection{The concept of Chinese Aesthetics}

Chinese aesthetics inherit the traditional style and incorporate modern fashion elements, inheriting traditional humanities, with modern manifestation, in line with the current people's living environment and aesthetic taste. The "Neo-Chinese style" is not limited to one aspect of design. It exists in modern home decoration design, apparel design, jewelry design, graphic design and fashion design. "Chinese Aesthetics" breaks the boundary between tradition and modernity.
From the perspective of fashion design, the design of Chinese aesthetic conveys the heritage of Chinese traditional culture. It is not a collage of several Chinese characters, large outline and blue and white porcelain patterns that can be called Chinese style design, which is also the simple understanding of Chinese style in western design for a long time. The biggest feature of Neo-Chinese style is to convey the charm of tradition, but not follow the tradition, it conveys an artistic conception. Chinese aesthetics adopts minimalist design techniques, with smooth lines and line elements are the basic elements of clothing modeling. They are filled in all kinds of clothing design in the form of local secant, pleated line and splicing line, and pay attention to coordinated, balanced, symmetrical and unified structural design. The characteristics of Chinese style are very obvious. It is a typical planar crop of oriental, and the streamlined is everywhere. It is also a cropping method. Chinese style clothing version is very comfortable and convenient, but it does not lose the sense of design. It has the characteristics of practicality. Chinese art was called "calligraphy and painting" in ancient times, so the colour has a sense of ink and wash. And there is a kind of thicker colour "DanQing", which is a typical representative of Chinese style and has the artistic conception of landscape painting. ${ }^{[2]}$

Independent aesthetics embodies freedom, individuality and diversity. These factors exactly meet the personalized psychological needs of consumers. 
Today's young people live in the era of Internet development. They are faced with increasingly diversified material culture and information culture every day. Modern culture is becoming more and more abstract and diversified, freeing this era from the shackles of many traditions. From the perspective of individual consumption, young consumers pursuing personalized clothing are the most significant embodiment. Individual consumption not only reflects the change of consumption concept, but also reflects the change of social membership. It is also because of individual consumption that the self-awareness of social members is also enhanced. The theory of individual consumption is consistent with the development of production technology.

Personal consumption is deeply influenced by the cultural environment. The number of consumers who want to participate in product customization design has increased sharply. They hope to design high-quality products so that consumers can express their opinions and consumer needs according to their own consciousness. The consumer groups of chaopai are eager to express different voices, which is also the personality and spirit that personalization wants to express. With the blending of cultures in different countries and regions, it promotes the collision of inspiration. This also makes clothing as a carrier of cultural communication have more far-reaching and unique significance. Moreover, the current era is an era of rapid development. Young people are eager to have personal emotions beyond reality and realize themselves between pursuit, dream and reality. Individual consumption is closely related to the improvement of the people's consumption level. With the rapid development of society and the improvement of living standards, consumption to meet their own desires will inevitably arise after meeting material requirements. They no longer only pay attention to the original function of the product, but also pay more attention to the cultural connotation of the product. I hope this product can reflect my personal taste. At the same time, the expansion of the market enables tangible goods to exceed demand and become rich, enabling consumers to make choices according to their preferences, which is also one of the factors leading to personal consumption.

\subsection{The formation of Chinese Aesthetics}

In the new period of the revival of Chinese traditional culture, due to the cultural thoughts of various changes, Chinese aesthetics was formed. With the development of national economy and culture, China has formed a relatively stable market economic system and people gradually pay attention to Chinese traditional culture while living and working in peace and contentment. Chinese aesthetics is a design style formed by the integration of traditional culture, the spirit of the times, modern consciousness and modern aesthetic integration.

Chinese aesthetics design is the favor of Chinese people's traditional culture. It is deeply rooted in the traditional culture of Chinese people. In the era of multiculturalism, the continuous infiltration of Western culture, Japanese and Korean culture has created a need for Chinese people to find their roots. However, traditional culture is not only blindly inherited, but also needs innovative design in line with contemporary aesthetics and needs and Chinese aesthetics is the product of this demand. Chinese aesthetics not only resonates with our own people, but also has been widely concerned by Western designers who have always been sensitive to Chinese elements. ${ }^{[3]}$

\subsection{The development of Chinese aesthetics}

In the 1980s and 1990s, due to the reform and opening up, the development of productivity appeared in the spoken language of the people. China pays attention to cultural diversity, Chinese and foreign culture affects Chinese design, resulting in many products with traditional elements and new era style. People have the name of "Neo-Chinese style" through "old Chinese style". At the beginning of the new Chinese design, the fields involved were architecture and interior design. With the development of the times, the "Neo-Chinese style" design style has appeared in the fields of clothing, plane, products and so on. In 2002, the word "Neo-Chinese style" officially appeared in the article and title of China National Knowledge Infrastructure (CNKI), and there were more theoretical studies on "Neo-Chinese style" in various home decoration, architecture and clothing. "Neo-Chinese style"also has a real definition: Chinese traditional style culture in the new interpretation of the new era, realizes contemporary design under the premise of traditional cultural masters.

\section{APPAREL DESIGN OF CHINESE AESTHETICS}

\subsection{Development of Chinese Aesthetics Design}

During the revolution of 1911, suits were introduced into China and prevailed in China. With the development of modernization, the traditional Chinese costumes are cumbersome and inconvenient, which was gradually unacceptable to people, at the same time, "improved Chinese costumes" appeared. With the rise and development of China's national strength, Chinese aesthetic clothing has gradually attracted the attention of the West. The Chinese style has been favored by the world, and the innovation and inheritance of Chinese people.With the Olympic Games, World Expo and other 
international events held in China, Chinese aesthetics has stood on the world stage. ${ }^{[4]}$

\subsection{The difference between "Chinese style" and "Chinese Aesthetics"}

In common, "Chinese style" and "Chinese Aesthetics" have Chinese traditional elements; all developed from the field of home decoration and architecture. Both inherit and carry forward the spirit of Chinese culture. The difference between the two originated, "Chinese Aesthetics" originated in China after the reform and opening up, while "Chinese style" originated in European furniture design. The "Chinese style" was very popular in European interior and textiles in the 17th-18th century. They called this style "Chinoiserie", which is an artistic style of Western style. It is an art with the interpretation of Western subjective consciousness. Most "Chinese style" designs only stay on the surface and do not understand the essence of Chinese traditional culture. They just copy and stack blindly, which is not suitable for the needs of modern people. At the beginning of the formation of "Chinese Aesthetics" style design in China, it adheres to the concept of keeping pace with the times and it is more the artistic conception of Chinese traditional culture.

\subsection{Chinese elements in Western fashion design}

Western designers have never stopped from Chinese traditional culture, whether in Europe, or today's international fashion design, there are Chinese elements in the Western design. However, due to the difference in cultural background, many Western designers do not understand the real Chinese culture. Its design is only on the surface, and the concept of "Chinese style clothing" is expressed, and it is not possible to discover the fashion, but also the communication with the world. Additionally, there are also some Western designs that truly understand the artistic conception of Chinese culture.

\section{DEVELOPMENT STATUS OF "CHINESE AESTHETICS" STYLE CLOTHING DESIGN}

With the prevalence of "Chinese style" in recent two years, it has a place in the global fashion, and major mainstream magazines are full of Chinese style in this year. There have also been many new Chinese fashion design shops, but there are still some problems of too traditional and outdated design. However, some local designers have also designed "Chinese Aesthetics" with unique fashionable style. ${ }^{[5]}$

\subsection{Chinese aggressive designer}

This year, the local fashion designer RuiZhou was shortlisted for the final of LVMH Grand Prix. The LVMH Grand Prix is one of the most important new designer awards in the world. In the past, Chinese designers were shortlisted every year, but Rui Zhou was the first to enter the finals. She regards clothing as the second layer of skin. By studying the space between skin and plants, body and clothing, entity and boundary, she applies the Danqing colour of Chinese elements to the clothing, which more interprets the artistic conception beauty of Chinese style.

This is an era of the rise of domestic products and young groups are passionate about many niche brands. ShushuTong, a well-known independent designer, is sought after by many bloggers with its avant-garde girl style and retro oriental colour matching. In addition, the cooperation with the Peace Bird were sold out, which is enough to confirm what the chairman of the Peace Bird group once said,"China has good design, good market and good brand."

\subsection{Current situation abroad}

The concept of sustainable development is the focus of the current global fashion industry. Due to the influence of this concept, slowly has become the development concept of international fashion, and the traditional exquisite workmanship of "new Chinese style", the sustainability of its fabrics, the emotional design and minimalism have been pursued and concerned by international fashion. "Chinese Aesthetics" is influenced by the aesthetic thought of "Zen". The texture is fitted with skin, cropping nature, designer pursues high quality original design, its unique Oriental Minor Become a new benchmark for foreign designers. Many international luxury brands have found that with the changes of the times, they continue to look back on the nourishment of traditional culture and art. Chanel has seven workshops, including logon pleat workshop, Lesage embroidery workshop. MarNi announced the launch of the "MarNi Miao Miao" cooperation project during the 2020 spring and summer Shanghai Fashion week. The project is entitled "just in time", which aims to "interpret fashion manufacturing from a contemporary perspective through the classic traditional crafts handed down from generation to generation". It can be seen that the era of blindly pursuing European and American fashion, Japanese and Korean fashion has passed. Under slow and fashionable return, the Chinese style is quiet and sustainable, and sustainability is the ideal of global fashion. ${ }^{[6]}$ 


\subsection{Development of Chinese Aesthetics in future}

In the post-epidemic era, many industries are waiting for reconstruction, including fashion industry. The style of "Chinese Aesthetics"stylehas emerged in the front and international styles, will gradually release its brand-new value. The sustainable industry is the general trend, and Chinese fashion should also seize this trend, give play to the unique advantages of Chinese style, push through the old and bring forth the new, not just stick to the "Chinese element", but combine it with Westernization to gain a firm foothold in international fashion. Now more and more aggressive designers are emerging in the world. I believe they will continue to bring Chinese fashion, Chinese culture and Chinese crafts to the international stage. Make Chinese design more confident on the international fashion stage.

China has become a big country in fashion consumption, and the design of Chinese minority brands is becoming more and more unique and fashionable. They have gradually moved towards the world with the unique mysterious beauty of the East. Chinese brands and Chinese designers will encounter more opportunities, which will be a new scene and new vitality for the development of China's fashion industry.

\section{CONCLUSION}

The design research of Chinese aesthetics makes the diversified design ability become a series of cognitive abilities. Outside the field of fashion design, the success of many brand design has been fully confirmed, so that we have such a kind of rational knowledge. On the road of aesthetic design, designers are not only designers, but also producers and communicators. Designers from different departments and fields or from different vertical development fields present a new challenge rule in creating a freely defined design to identify isolated areas, create new opportunities, and integrate activities with new links. Although these activities belong to different fields, they are often related to reality. By better understanding other people's customers, we can inject new impact into new cooperation among professionals. A characteristic of design behavior is to constantly create new things and restore traditional things, so that the design work has the characteristics of product environment. The way of taking multiple actions after product design provides a complex and interesting design basis for the definition of freedom.

Chinese fashion has been the existence of curiosity and appreciation in the world since ancient times. Although Western designers love it, they don't understand it. The design of Chinese elements is always in the surface, but as China gradually moves towards the world, the world has seen the real Chinese beauty, Chinese beauty behind the appearance. Chinese brand and Chinese designers have gradually moved towards international fashion, and it is very large in the stage of the world.

\section{REFERENCES}

[1]Gang Ma, A perspective on new Chinese-styled architecture and its development, China Building Materials Science and Technology,2015,24(06):100-101.

ShengnanLi, Hong Dai, "Chinoiserie" and "Neo-Chinese style" in fashion design, Industrial design,2019(02):120-121.

[2]Xing Zhou, Practical,Inclusive and Open "Chinese Garment" (I), Journal of Clothing Research,2018,3(01):59-66.

[3]Mingxin Bao, Chinoiserie in European textiles and costume,Journal of China Texfile University, 1987(01):91-97.

[4]Fang Liu, The application of "Neo-Chinese style" fashion design concept,Jiannanliterature,2012(04):151.

[5]Huina Lu, Neo-Chinese styleclothing research under slow and fashion return, Art science and tTechnology,2016,29(05):138.

[6]Zheng Dong, Global fashion interaction in the post epidemic era, China textile,2021(Z1):50-53. 